\title{
The Informal Channels of Indigenous Tenants in Coping with the Inefficient Bureaucracy of the Gezira Scheme, Sudan
}

\author{
El-Tom, Abdullahi O., Ph. D., Lecturer, St. Patrick's College, Department of \\ Anthropology, Maynooth, Co. Kildare, Ireland; \\ Nur El-Dayem Osman, Senior Researcher, Faisal Islamic Bank, Khartoum, Sudan
}

\begin{abstract}
This paper examines the management of irrigation in the Gezira Scheme, Sudan. It focuses on the tenants' management of water at the farm level. The authors argue that despite several decades of top-down instructions, Gezira Scheme tenants still retain their indigenous agricultural calendar. The calendar contains description of weather, rain, pests and possible yields and accordingly prescribes specific agricultural activities. This gives rise to informal channels of action which often contradict official instructions. Unlike the management of the Gezira Scheme, the authors do not take the informal channels as indicative of the tenants' lack of discipline, laziness or ignorance. Rather, they constitute innovative and practical response to Scheme inefficiency and bureaucratic rigidity. Most importantly, the adoption of these informal channels renders agricultural operations both. practical and economically viable.
\end{abstract}

\section{Prelude}

On one of the typical days of December 1987 in a typical tenants village in the Gezira, a group of farmers were listening to a programme broadcasted by Radio Medani, Central Region. The Broadcaster went on as follows:

"Farmers are advised to start cotton picking from the section of the tenancy adjacent to Abu XX canal (angaya) and then move away from the canal to the end of the tenancy."

A loud laughter of amusement came from the farmers surrounding the transistor radio. One of them shouted in a cynical way:

\footnotetext{
"This is yet another Gezira Scheme official reading from his books; that systematic cultivation was abandoned ages ago. For lack of water, the practice of watering, sowing and picking of cotton from the canal away to the end of the tenancy has been reversed by the farmers for years and years and those people still stick to their old and invalid books."
}

\section{Introduction}

This article deals with the farmers' management of irrigation in the Gezira Scheme. The article is based on a research conducted with the aim of identifying methods of conserving water as a part of the Scheme rehabilitation plans in the late 1980s. The Scheme was established in the 1920 s in the area between the Blue and the While Nile south of their confluence at Khartoum. Since its establishment, the Scheme continued to be the backbone of Sudan economy accounting for around $60 \%$ of export revenue. It has also continued to be dominated by cotton cultivation although some food crops are also grown in the Scheme.

Once described as "Africa's most successful agricultural venture ever", the Gezira Scheme has long passed its golden age. After sixty years of instructions from the agricultural inspectors, the tenants of the Gezira Scheme are still retaining their separate agricultural calendar. This calendar is virtually unknown to the majority of the bureaucrats of the Scheme and is therefore unaccounted for in the top down decision making process. Indeed, it was assumed that the pre-Scheme peasant agricultural system which was based on rainfed cultivation (June to November) was irrelevant to the new and albeit modern system of irrigated agriculture. It was therefore expected that continuous supervision, training and extension would lead to the replacement of the old and archaic agricultural system by a modern one based on scientific experiment. This is partially responsible for ignoring the farmers' knowledge in the irrigation planning in the Gezira Scheme. Needless to say, the divergence between the official agricultural system and its peasant counterpart is liable to lead to lack of strict adherence to the agricultural instructions in the Scheme. Understanding of the farmers' agricultural calendar is therefore necessary in order to accommodate the differences between the two systems. 


\section{Farmers' Agricultural Calendar}

The present agricultural calendar narrated by the studied farmers evolves from two distinct systems. The first one is referred to as El-Kabbashi. The term itself is derived from the name of its famous propagator who died about a century ago. The second system referred to as Sabbag, a term whose origin is not known to us. The calendar divides the year, or at least the active part of it, into a number of equal durations (Eenat, sing. Eena). Each Eena is 13 to 13.5 days long. An Eena is characterised by specific weather which influences agricultural activities. The calender also includes instructions to farmers on various activities:

Farmers' Agricultural Calendar

Eena:

Saratan (Cancer), is also referred to as Natra.

Duration: Characteristics: 22nd April to 5th May

Eena:

Duration: Characteristics: Intense heat (unhealthy) and dusty winds (haboob).

Butain

5th May to 18th May

Deterioration of pasture; rain damaging to pasture and health; rain unsuitable for cultivation; sharp increase in prices of sorghum.

Eena:

Duration:

Characteristics:

Thuraya

18th May to 31st May

Intense heat; animals miscarry; chicken eggs go rotten.

Eena: Dubran

Duration: Characteristics: 31st May to 13th June

Eena:

Duration:

Characteristics:

Eena:

Duration:

Characteristics:

Eena:

Duration:

Characteristics:

Eena:

Duration: Characteristics:

Heavy winds.

El-Hagaa

13th June to 26th June

Winds continue; cloudy; occasional deceptive showers.

\section{Hanaa}

26th June to 9th July

Autumn proper begins at the end of this Eena. Complete preparation of tools and seeds and labour for agriculture; end of slack period of the "year"; best for growing groundnuts; not good for sowing sorghum.

Duraa

9 th July to 22 nd July

Sorghum sown at this Eena gives best results; good for sowing groundnuts, tomatoes and onions.

Natra

22nd July to 4th August
Eena:

Duration:

Characteristics:

Eena:

Duration:

Characteristics:

Eena:

Duration:

Characteristics:

Eena:

Duration:

Characteristics:

Eena:

Duration:

Characteristics:

Spread of pests (grasshoppers, locusts, mice, etc.); no good for sowing of any kind as seeds will be destroyed by pests.

\section{Eena: \\ Duration: Characteristics:}

Tarfa

4th August to 31st August

Mist is a feature of this Eena; uncompleted sowing of sorghum may be resumed; good for sowing cotton but not goundnuts.

\section{El-Jabha}

17th August to 31st August

Hot; likelihood of heavy rains. Resume sowing cotton but sow no vegetables.

\section{El-Kharasa}

31st August to 13th September

Its rains mark the end of autumn, is good for plants. Sow tomatoes and onions. Last chance for late sowing of cotton; cotton sown earlier if attended to will flourish in this Eena. Desperate late sowing of sorghum will be rescued by winter.

\section{El-serf}

13th September to 26th September

Good for growing tomatoes, cucumbers and onions. Temperature starts dropping making it possible to start growing wheat at the end of this Eena.

\section{El-Eiwa}

26th September to 9th October

Temperature continues dropping and winter winds start; good for sowing wheat, vegetables and horse beans

\section{El-Simak}

9th October to 22nd October

Real beginning of winter and its winds. Finish the sowing started in previous Eena.

It is obvious that the above calendar evolves from a system primarily developed for rainfed agriculture. The calendar is also adapted to the present system of agriculture as evident from the instructions on sowing going far beyond the rainy season. The system does not only combine prediction on rain, temperature, pasture, pests and yields but it also gives clear advice on which activity to be pursued at any Eena. Our findings here however overlap with the official and semi official calendar specially with regards to sowing. For cotton, groundnuts and sorghum, our system recommends sowing to take place at later dates. With regard to wheat, our system seems to favour the sowing to start earlier and also finish earlier than the reported results. Needless to say that a change in sowing also implies a concommitant shift in prewatering dates. 


\section{Who Irrigates?}

For the tenants, irrigation is the most important agricultural activity which should not be left to hired workers to perform. Exception occurs in the case of using an agent (wakeel), renting the tenancy or resorting to sharecropping. The tenants also assume that the workers, some of whom are indeed transitory to the Scheme, do not have sufficient knowledge of modern irrigation. The comparatively low status of the workers is also assumed to make it difficult for them to deal efficiently with other tenants and indeed with the ghafirs (water bailiffs). Sharecropping and renting of tenancy however mean that many workers might also be involved in irrigation. According to our investigation which covered 126 tenants for three different categories of crops, sharecropping for (i) cotton and wheat, (ii) sorghum/groundnuts and (iii) vegetable was running at the rate of $4.8 \%, 66.7 \%$ and $25.4 \%$ respectively. Renting of tenancies for the same crops was $0 \%, 0 \%$ and $66.7 \%$ respectively. It is important to note here that some of the sharecroppers and those cultivating by rent may also belong to the same tenants' ethnic groups (Tab 1).

Tab 1 shows that a considerable number of those involved in watering might not be tenants. This necessitates a change in agricultural extension currently addressing tenants through $\mathrm{TV}$, radio, films, etc. in matters pertaining to irrigation and other agricultural activities. It is to be noted that transistor radios are owned by $81 \%$ of tenants while TVs are owned by only $55 \%$ of the studied population. This finding outlines the limitation of TVs in disseminating such important knowledge. Compared to the tenants, the workers own even fewer transistor radios and certainly no TVs. If ever the message is to get through, addressing the workers in any extension work also requires a drastic shift from the current elitist language used in the media to simple Arabic or perhaps other languages spoken by workers.

\section{Methods of Irrigation}

According to the Gezira tenants,

"Crop watering is the most important activity for the growth of the plant. It is also the most demanding job and has to be performed with high levels of skill, dedication and ingenuity. Shrewdness, knowledge of the official regulations and how to manipulate and avoid them are also important qualities for the water user. In the past, (and the tenants are famous for glorifying the past of the Gezira Scheme) watering involved little confrontation with other tenants, bailiffs and other officials. That was mainly because the canals were well maintained, the bailiffs carried out their responsibilities and the available system of communication enabled the tenants to communicate their requests in a satisfactory manner. Now things have changed. There is rarely enough water in the canals at pertinent times. We often have to steal it, bribe the bailiffs to get it or tamper with its level to irrigate our crops in time."

Overlooking the exaggeration in the above quotation, one can still find some justification for the grudges aimed at the present state of irrigation in the Scheme. The

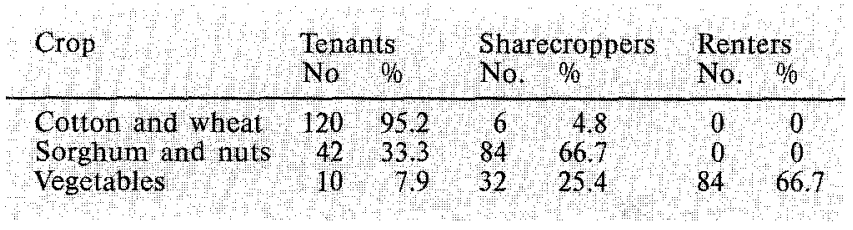

Tab 1 Who cultivates

expansion of the Scheme and its intensification have put an extra strain on its management and have obviously affected the level of water delivery as well. A part of the success of the Gezira Scheme was due to its ability to keep the cost of management down. The inspector to tenant ratio of $1: 250$ reported nearly 20 years ago has not changed much and the same high burden applies to many departments in the Scheme. Pertinent to the marginal improvement which could be obtained by increasing the official to tenant ratio in the Scheme is the conclusion that irrigated agriculture is the most expensive mode of agriculture in the Sudan.

Like many other official segments in the country, the Gezira Scheme has not been able to develop an efficient tradition of maintenance. Lack of maintenance could be observed everywhere in the Scheme; phone system, roads, buildings, canals, etc. Crop watering has undoubtedly been affected by this lack of maintenance. Without clinging to the myth that tenants were more disciplined in the past, if the cultivated crop is to survive, the present water delivery makes it inevitable to breach the text regulations. The following is a summary of the current watering practices recorded by ourselves.

The ideal watering practice is to divide tenancies along Abu 'Ishriin-canal into two units. The head unit which consists of the first four tenancies will be watered within four days. The farmers of the second unit (five tail tenancies) delay their irrigation until the head tenancies have finished watering. Little or no tampering with the canals and the level of water in it takes place in this ideal system. Such a method of irrigation is only possible under the following conditions:

1) When tenants are convinced that water is plentiful and will remain so for a few days to come.

2) When crops are not too desperate for water and will not be seriously affected in the event of a sudden breakage of water delivery.

When these conditions prevail, farmers along the canal collaborate and undertake watering in the manner described above. Things, however, do not always remain equal and the resort to other - unorthodox - practices has to be pursued. When the water is available but falls slightly below the perceived convenient level, then there is still room for order and collaboration among Abu 'Ishriin tenants. Using mud, a small dam is constructed in Abu 'Ishriin-canal just at the point separating the head and tail units. Occasionally the mud heap is replaced by sacks of mud. The use of sacks is however a laborious task requiring 
the collaboration of a group of farmers. This practice is regarded as "more illegal" and is therefore done strictly behind the Scheme officials and sub-officials. The use of sacks is sometimes done behind the eyes of tail tenants who normally object unless they are sure that the sacks will be removed afterwards.

If a single dam in Abu 'Ishriin-canal is not enough for raising water to the convenient level, then a resort to a different practice is invoked. A single dam is made for every single tenancy starting from the head one. This is a much slower practice and it therefore involves conflicts among Abu 'Ishriin tenants mostly due to overworry about water and speed of irrigation. If the tenants are not satisfied with the level of water, then the FOP (Field Outlet Pipe) joining the Minor canal with Abu 'Ishriin can be manipulated to ease the problem. Indeed the head and tail enders are in continuous dispute about the state of MinorAbu 'Ishriin connection. It is now a common scene to see the slice of the FOP used in farmers' kitchens as a Kisra (pancake) griddle. While tenants at the head may be worried about overflooding in the event of an unmaintained canal, they often resort to keeping the FOP closed and therefore stop water from flowing into $\mathrm{Abu}$ 'Ishriin-canal. Tail enders, on the other hand, steal the slice or throw it in the water to ensure a continuous flow into Abu 'Ishriin-canal.

Tampering with the water control in the Minor canal is a more drastic measure followed by the tenants in their plight to ensure better irrigation. Depending on the position of the tenancies, both the head and cross regulators at the Minor canal can be lowered or raised at will by removing or replacing some of the bricks forming the weir. Desperate situations may also lead to breaking the canal itself if the FOP proved difficult to manipulate. A similar case was reported in August 1987 when a group of tenants attacked the Minor late at night, broke it and irrigated their fields. Two of the tenants were subsequently arrested after being reported to the Inspector in charge and their only defense was that they could not wait and watch their crops drying out. The arrested tenants were eventually released after the inspector reported that their relatives were able to restore the canal to its former shape.

According to our investigation, the Major canal itself is not immune against the hands of the tenants. The help of the bailiff is often secured by all means to do the job. If that is not possible for whatever reason, then there is nothing to worry about. A special wrench, a rope and a bamboo stick are all that the tenants need to open the Major canal, keep the water flowing and render the services of the bailiff unnesessary. Should the bailiff still prove an obstacle, he and it is always he - can be approached through his relatives, bribed or even threatened with violence. At most, he can only report the matter to the inspector and in that event, a good apology might settle the problem. Tampering with either the Minor or Major canals is a continuous cause of conflict among tenants along these two canals. While some tenants try to close them in order to raise the level of water, those further ahead do exactly the opposite to keep the flow in motion. The interference of the tenants in these canals and indeed the practices of many bailiffs make a mockery of the Night Storage System which prohibits irrigation during the night. The engineers themselves sometimes confiscate the canal gate openers to stop their bailiffs from yielding to the demand of the tenants and in so doing disrupt the official watering system.

In talking about blatant breaking of the rules, a mention must be made to reverse irrigation referred to as nakoosi. This is simply the practice of irrigating a tenancy through an outlet of water made on the reverse direction of other Abu arba'a canal at Abu 'Ishriin-canal. A nakoosi could also be extended from Minor canals. Permission is likely to be obtained from the Block Inspector to use such a method of irrigation in at least the following cases:

1) When the tenancy is too high to be irrigated from its respective canal.

2) When the respective canal is not maintained to permit irrigation of the tenancy.

3) When the newly established fruit gardens cannot be irrigated from the respective canals.

Block Inspectors are always reluctant to give permission to allow the use of this method in order to discourage its institutionalisation and thus make it a common practice. The practice also invites complaints from other tenants whose flow is reduced by such a nakoosi. The tenants on the other hand are unlikely to ask for permission to use this method unless they are sure that their request will be met favourably by the Inspector. If they ever asked and fail to obtain the permission, then they cannot go ahead with it without expecting severe punishment. Once the tenants decide that it is necessary to use a nakoosi, they simply go ahead with it. In most cases they will be pardoned provided that they remove these canals without forcing the Inspector to use hired labour charging it to their accounts.

\section{Watering of Different Crops}

\section{Cotton}

A number of variables have to be taken into account in talking about crop watering. These variables range from the type of crop under investigation, stage of the growth of the crop, level of humidity, expectation of future rainfall, intensity of heat and wind, degree of supervision from the part of the management, availablility and cost of labour, agricultural activity preceding or following watering, etc. These variables do not only affect the amount of water to be released, but also the method used to adjust its flow in the tenancy.

The most demanding crop in watering is cotton which is also a subject of tight supervision from the management. There are also some indications that cotton is by far more sensitive to changes in watering than other crops cultivated in the Scheme. In general, cotton requires watering every 12 to 15 days with a total number of around 18 waterings. 
The following constitutes only the major waterings of this crop:

Before sowing and/or ploughing.

After sowing.

After resowing (rugaa).

After use of herbicides.

After use of fertilizer.

At the flowering stage.

During harvesting (Acala type only).

Immediately after cotton sowing, one has to water the tenancy. The amount of watering depends on whether there has been presowing watering or not. The extent of presowing watering also determines the amount of water to be released into the tenancy. Care should be taken not to overwater the tenancy and therefore lead to the rotting of the seeds. Too little water may lead to abortive germination of the seeds as well. Soon the tenancy has to be revisited for reseeding within five to ten days. The following watering may be delayed until after the clearing of weeds and it is mostly light. Clearing of weeds continues together with the process of thinning which takes place during this period. Rain is mostly expected at this time and that has to be considered in watering the cotton. Fertilizer is used soon and the farrows are reestablished before the next watering. From now on, watering should continue with 12 to 15 day intervals until the harvest time. Subject to the availability of labour, watering should be done soon after the first cotton picking. If labour is not available, the watering should be delayed to avoid having the ripe cotton fall into the water. This, however, applies only to the long staple cotton (barakat' shambat). In the case of the short staple cotton (acala), there is no danger of the cotton falling into the water and it is therefore possible to continue watering until labour is secured.

\section{Sorghum and Groundnuts}

The watering of sorghum and groundnuts is relaxed and carried out with little interference from the management of the Scheme. Although the majority of the tenants opt for the tagnant (dike or bund) as the standard method of irrigating these two crops, some still manage to find time for the labour intensive ditches (jadwals) especially when the crops are small. Unlike with cotton, the farmers here are at ease to use their imagination with regards to the number of ditches to be used. This is also necessitated by the fact that both goundnuts and sorghum are often grown on inferior soils.

Sowing for both sorghum and groundnuts takes place before watering the land. Like cotton, resowing of these two crops is also followed by watering. In general, most tenants prefer watering to continue at the interval of 12 to 16 days. Watering is also regarded as extremely necessary during the flowering stage of groundnuts and during the ripening of sorghum.
Wheat

The sowing of wheat seems ot be preceded by much work compared to other crops. There ist first ploughing (fathia) and second ploughing (hirata) in addition to the preparation of ditches and tagnats. As cotton will be competing for water against wheat, the tenancy must be well prepared so that should the need arise, water could be quickly diverted from the former crop to the latter. The preparation of ditches mentioned above should not indicate that they will be used one after another in watering. In fact, the whole tenancy is divided into three sections and the method of flooding each section at a time provides the main framework for watering the wheat tenancy. Given a high flow of water, tenants at the head may be able to water their tenancies within a single day or a little longer. Those at the middle or tail spend much longer time than that and it is not unusual for some to interrupt their watering for two days and wait for the level of water to rise. Compared to cotton, the watering of wheat received less scrutiny from the Scheme supervision and the farmers, therefore, have a better chance to choose the method they see fit for irrigation.

The above paragraphs indicate that there are generally two methods of irrigation. A systematic and stage by stage irrigation following the ditches and farrows (angaya) and irrigation by flooding the whole tenancy, half or a third of it at a time. The first system corresponds to the text book system which is favoured by the Scheme and officially believed to conserve water. This is however less popular among tenants and is only followed up to a degree for the satisfaction of the management of the Scheme. This is mainly because the system of stage by stage irrigation is labour intensive. In terms of land preparation ie digging the farrows and ditches, it costs as much as $150 \%$ more than what is required for flood irrigation systems. In terms of irrigation, the stage by stage method also requires much more time than the other system. In abandoning it in favour of the flooding system, the tenants are said to have been able to reduce the time needed for irrigation in a brilliant fashion. It was reported in the 1970s that such method could reduce the time needed for irrigating a 7.7 ha tenancy from $468 \mathrm{man} /$ hour per crop to 17.

The farmers, however, have a say here: the stage by stage method is not without its disadvantages. When the crop is small, flooding could be quite damaging. Moreover, if the tenancy is not evenly levelled, flood irrigation leads to the concentration of water on the lower part of the tenancy and to partial overflooding and inadequate irrigation of the higher parts of the tenancy.

As it is already implied, a flood irrigation system is less demanding and less costly. It is also more appropriate when the crop is high above the ground and in which case the farmer must avoid excessive movement between plants. Re-establishing the ditches at this stage of the growth of the plant is also damaging for the plants. Needless to say, this system requires minimum supervision from the part of the water user. Should the watering 
continue through the night, the farmers can simply reduce the flow of water by tampering with the Minor canal and leave the farm overnight without worrying about overflooding. As I mentioned before, the only problem is the fear of partial overflooding of the tenancy if the land is not well levelled. This however increases the time input in supervision rather than rendering the whole method inappropriate. Flood irrigation is also aided by the nature of the Gezira clay. The swelling of the clay ensures that water flows away from wet to dry parts of the tenancy.

\section{Gezira Scheme Bureaucracy}

The Gezira Scheme is run by a rigid bureaucratic system marked by its high centralisation of decision making. Once a decision is made, it is often adopted with little consideration to local variations. With such a huge Scheme, it is obvious that the easiest way to run it is through managerial adherence to rigid textbooks. The problem is that this rigid bureaucracy has outgrown its ability to sustain itself. Ironically speaking, this bureaucratic system is surviving not because of successful bureaucratic management but because of the ability of the farmers to get around it. The farmers are no longer passive recipients of instructions on new methods of cultivation. They have already mastered the rigour of the imposed system of informal channels to deal with its bureaucracy. The system of informal channels which highlights the innovativeness of tenants is developed in order to help tenants breaking even and to cushion the rigidity and the inefficiency of the Scheme-bureaucracy. Let me use water requests as an example of bureaucratic sequences required in water delivery. In order to put forward a request for more water, the message moves from the tenants to the local bailiff then to the head bailiff (GB) then to the Block Inspector, then to the Irrigation Engineer who will instruct MOI (Ministry of Irrigation) bailiff to release the increment of water required. With the communication system under virtual collapse, one could imagine how long the process will take. If it ever rained when the request for water was still on its way, the tenants were in real trouble. With little prospects of reversing the order in time, then a resort to the informal channels was indeed a necessity. The local bailiff is instrumental in carrying out the orders of the Scheme but so too is he in delivering the unofficial requests of the tenants. When the Scheme started, the bailiffs were mostly imported from outside the peasants' community. They were a part of the management machinery and they lived in houses provided by the Scheme and located in accessible places near the canals which they were paid to attend to. Nowadays most of the bailiffs are local and they have deserted their official houses in favour of the tenants' villages where they belong. Their position has indeed become precarious as they are caught up between their obligations to their kin tenants and their duties to the managerial class to which they often aspire to belong. In order to keep his job, the bailiff has to convince his superior that he is satisfactorily executing the orders. At the same time, the bailiff acknowledges his obligations to the tenants, not to mention his awareness that he cannot survive on his meagre salary. As I implied before, the bailiff can be approached by the tenants invoking kinship and/or neighbourhood obligations, can be threatened with violence, beaten up or bribed. This is done to officiate an illegal act or at least to turn a blind eye when the tenants go against the rules. The bribery of the bailiffs is so institutionalised in the tenants' community that during the wheat and sorghum harvest time, the bailiff moves with his empty sacks from one farm to the other to collect his informal tributes.

In order to maximise their gains or simply to break even, tenants have also extended their informal dealings in order to raise their shares in the crops produced. It is normal for tenants to pick up some cotton and sell it to the local merchants; an illegal pratice as all cotton should be handed over to the Scheme. Through bribing those who are in charge of threshing wheat and recording the amount harvested, tenants can also declare a lower output and therefore increase their share in the produce.

In enlisting the above dealings, we are neither interested in exposing the tenants to the management of the Scheme nor in covering all their illicit practices. Indeed, we feel that the Scheme is fully aware of most of these dealings but is deliberately opting to keep its so-called "official coolness". Those who are interested in capturing other means of rule twisting employed by the tenants may turn to diversion of fertilizers and other chemicals to the market or to other crops, renting and sale of tenancies, sharecropping, off-tenancy activities, animal breeding, absenteeism, etc. For our part, we would like to state here that these informal channels have been adopted to face the rigidity of the Scheme, its inefficiency and lack of realism. Such channels also indicate the innovativeness of tenants and how they have been able to survive. Those who are sympathetic to the tenants are not without a reason to rejoice. By developing these "off-the-text-book-channels", the tenants deserve the credit for helping the system to keep going.

\section{Tenants' Views on NSS}

The present water delivery system in the Gezira is indeed chaotic and difficult to describe. It cannot be described as a "night storage system" (NSS) because irrigation takes place at night as well. It is hardly a system of continuous flow because the water does not flow continuously and both the design of the canals and the managerial practices indicate otherwise. In a questionnaire which covered 60 farmers distributed along Hamza Minor Canal, $95 \%$ of the informants expressed their dissatisfaction with the present system. The tenants seem to have been tired of tampering with the canals and with the performance of their own Production Committees. Accepting their subordinate position in the management of 
the Scheme, $85 \%$ of our interviewed tenants favoured a system of irrigation where the water discharge will be strictly controlled by the Inspector and his staff. This gesture, however, is not without its conditions: canals must be maintained, bailiffs must do their job properly and the water must be delivered in time. Given the current constraints of the Gezira Scheme, we are aware that these conditions are not easy to meet. An important message to be learned from the tenants here is that their interference in water delivery is necessitated by the inefficiency of the system and that an improvement in the official management of water is likely to induce a decrease in their meddling with water discharge.

\section{Conclusion}

The paper shows the tenants are not passive recipients of orders from the management of the Scheme; they have their theories and they have developed their techniques of turning the system to suit their needs. Whether the tenants resort to the informal channels constituting corruption, lack of discipline or innovation is beside the point. Our reference to the informal channels as indicative of tenants' innovation should not in any way imply that we condone bribery or destructions of canals. Pertinent questions here are why the tenants go informal and how to reduce the gap between the official and the unofficial practices. The following few lines may help towards the elimination of at least some of the problems under investigation.

The informal channels are, primarily, developed to cope with the lack of adequate responses to tenants' water problems. Without conjecturing on the ability of the Scheme to make water available for all the current cultivated crops, lack of appropriate response cannot be avoided without adequate maintenance of the canals and improving the system of communication which affects water delivery. If that can be done, and we see no reason why it should not, repetitive successful responses from the Scheme will also help restore the confidence of tenants in the official management of water and hence eliminate many unnecessary practices of the farmers. Although the tenants are not experts in the management of water above the farm level, they still point to the frequent lack of coordination between the Scheme (Ministry of Agricuiture) and the Ministry of Irrigation and its alleged negative impact on water delivery. Many of them suggest that the Scheme should be fully in charge of all the canals. However, the managers of the Scheme may wish to look at this suggestion, the fact remains that the present system complicates the management of water and places some of the canals in the hands of those whose primary concern is not the welfare of the cultivated crop.
Pertinent to our problems here is also the question of divergent priorities of the Scheme management and their tenants. For the tenants, priority goes to the conservation of labour and time invested in irrigation in addition to precedence of sorghum over cotton. In sharp contrast to that is the Scheme's emphasis on water conservation and preference of cotton over sorghum. Such differences must be resolved in order to reduce conflicts in water practices. As sorghum requires little watering compared to cotton, plans must be made to ensure meeting its water requirement and indeed we see no reason for not giving priority to food production in the Scheme and indeed in a famine stricken country. The share of the tenants in cotton production could also be made more attractive. Prompt payment of tenants' share in cotton could encourage many farmers not only to put more efforts in cotton but equally to be able to make more accurate correlation between their efforts and their gains. Under the present tenants' work load and their current share in the proceeds of crops, there is no way out of flood irrigation. As we have no adequate knowledge of how wasteful this method is when compared with the ditch method, we cannot recommend its officiation. Future research may help to resolve this issue.

We have already touched on many issues regarding closing the gap between the tenants and the management in the field of water use and delivery. The gap cannot be closed without getting the management and the tenants to adopt the same views and practices. In a setting in which the management and the tenants constitute two separate classes, this is indeed a problem which is difficult to solve. Familiarity with tenants' theories and practices requires contacts which must go beyond honouring tenants' wedding and circumcision ceremonies by top officials. As long as the Inspectors and other top officials avoid getting their feet muddy and as long as getting inside the schisto infested water of the canal is a taboo, the problem will not go away and the gap will remain wide. We realise that a partial solution of the problem can be effected by encouraging the top officials to go dirty and by selecting a cadre which does not shy away from getting muddy feet but above all by decontaminating all the canal water. This will, however, only reduce the gap whose full elimination requires fundamental changes in the Scheme and which cannot be adequately dealt with in this paper.

\footnotetext{
* This paper is based on a research conducted in 1987/1989. Full details on bibliographic sources can be found in: Farm Level Study of Water Management in the Gezira Scheme. Hydraulic Research Station, Medani 1989.
} 